\title{
Electronic Perspective on the Electrochemistry of Prussian Blue Films
}

\author{
J. Agrisuelas, ${ }^{a}$ P. R. Bueno, ${ }^{\mathrm{b}}$ F. F. Ferreira, ${ }^{\mathrm{c}}$ C. Gabrielli, ${ }^{\mathrm{d}, *}$ J. J. García-Jareño, ${ }^{\mathrm{a}}$ \\ D. Gimenez-Romero, ${ }^{\mathrm{a}, *, \mathrm{z}}$ H. Perrot, ${ }^{\mathrm{d}, *}$ and F. Vicente ${ }^{\mathrm{a}, *}$ \\ ${ }^{a}$ Department of Physical Chemistry, University of Valencia, 46100 Burjassot, Spain \\ ${ }^{b}$ Institute of Chemistry, Estadual Paulista University, 14801-907, Araraquara, São Paulo, Brazil \\ ${ }^{c}$ Laboratório Nacional de Luz Síncrotron, 13083-970, Campinas, São Paulo, Brazil \\ ${ }^{d}$ UPR 15 of CNRS Laboratoire of Interfaces et Systèmes Electrochimiques, Université Pierre et Marie \\ Curie, 75252 Paris Cedex 05, France
}

The derivative of the voltabsommetric scans, together with previous nano-electrogravimetric and X-ray diffraction results, allow different electrochemical processes to be distinguished during the Prussian blue (PB) voltammetric scan. Potassium, proton, and hydrated proton counterions involved in PB electrochemistry are related here to the electrochemical reactions of specific Fe sites. Potassium counterions show two different sites for their insertion: one located in the crystalline framework and another in ferrocyanide vacancies. From the monitoring of electroactive Fe sites, the covalent-exchange model is suggested as one of the first approaches to explain the origin of the PB magnetic ordering observed at room temperature during voltammetric scanning. (C) 2009 The Electrochemical Society. [DOI: 10.1149/1.3080711] All rights reserved.

Manuscript submitted November 10, 2008; revised manuscript received January 21, 2009. Published February 20, 2009. This was Paper 197 presented at the Honolulu, Hawaii, Meeting of the Society, October 12-17, 2008.

Systems that undergo reversible and controlled changes of their properties offer appealing perspectives for the fabrication of electronic switch devices. Thus, Prussian blue (PB)-like materials have raised intense interest because of their electrochromic, ionexchange, ion-sensing, electrocatalytic, or photomagnetic properties, ${ }^{1-5}$ because the $\mathrm{PB} \rightleftarrows$ Everitt's salt (ES) voltammetric scan is accompanied by reversible changes in these physicochemical properties. ${ }^{6-10}$ Likewise, they also display a wide range of important magnetic (e.g., room temperature magnetic ordering) and magnetooptical (e.g., ferromagnetism, photoinduced (de)-magnetization) properties. ${ }^{11-14}$ In particular, the PB electromagnetic properties can also be tailored by external conditions, such as the magnetic field, ${ }^{15-17}$ light, ${ }^{15,18,19}$ and by electrochemical methods. ${ }^{18,20-24}$

$\mathrm{X}$-ray studies showed that the PB three-dimensional (3D) structure is face-centered cubic $^{25}$ with a general formula equal to $\mathrm{Fe}_{4}\left[\mathrm{Fe}(\mathrm{CN})_{6}\right]_{3} \cdot \mathrm{mH}_{2} \mathrm{O}$. Trivalent and divalent iron ions are in highand low-spin sites, $\mathrm{Fe}(\mathrm{III})_{\text {high-spin }}$ and $\mathrm{Fe}(\mathrm{II})_{\text {low-spin }}$, respectively. ${ }^{26}$ Enclosed in this structure, high- and low-spin sites are both octahedral and surrounded by $-\mathrm{NC}$ and $-\mathrm{CN}$ units, respectively. Thus, the PB lattice is composed of repetitive units of $\mathrm{Fe}_{\text {low-spin }}-\mathrm{CN}-\mathrm{Fe}_{\text {high-spin }}$ in the three spatial directions. Nonetheless, $\frac{1}{4}$ of low-spin Fe(II) sites are missing and occupied by water molecules coordinated to $\mathrm{Fe}(\mathrm{III})_{\text {high-spin }}$ ions. The PB structure is completed with water molecules occupying interstitial positions. ${ }^{27-29}$

The above crystalline structure corresponds to the freshly deposited PB film following the electrochemical methodology described by Itaya et al. $^{22}$ and it is known as insoluble. The insoluble PB is electrochemically converted into the soluble PB by means of successive voltammetric cycles between the $\mathrm{PB}$ and ES forms ${ }^{30,31}$ until a stable electrochemical response is achieved. ${ }^{32}$ The soluble PB has been described as similar to the insoluble $\mathrm{PB}$ 3D structure. ${ }^{33,34}$ Repetitive structural units of $\mathrm{Fe}_{\text {low-spin }}-\mathrm{CN}-\mathrm{Fe}_{\text {high-spin }}$ also compose its rigid framework, where $\frac{1}{4}$ of the low-spin sites are missing. The position of the trivalent iron ions can be drawn as $\mathrm{Fe}(\mathrm{II})_{\text {low-spin }}-\mathrm{CN}-\mathrm{Fe}(\mathrm{III})_{\text {high-spin }}$ and $\mathrm{Fe}(\mathrm{III})_{\text {low-spin }}-\mathrm{CN}-\mathrm{Fe}(\mathrm{II})_{\text {high-spin }}$ sites. Spectroscopic techniques allow the amount of these sites to be monitored through the spectral transitions at 380,686 , and $1000 \mathrm{~nm}^{35}$

During the voltammetric scan between the soluble PB and ES forms, changes of oxidation states of trivalent iron ions are accom-

\footnotetext{
Electrochemical Society Active Member

z E-mail: David.Gimenez-Romero@uv.es
}

panied by the exchange of counterions to reach the film electroneutrality. ${ }^{20,21,29,36-40}$ In potassium salt solutions, these counterions are potassium cations, hydrated protons, and protons. Furthermore, a structural changeover occurs during this scan within a very narrow potential range. ${ }^{7,8}$ This changeover implies an extra electric current induced by the PB magnetic ordering. ${ }^{8}$

The main goal of this work is to distinguish the electrochemical reactions of the different electroactive Fe sites that compose the PB structure during the $\mathrm{PB} \rightleftarrows \mathrm{ES}$ voltammetric scan. This study is based directly on new spectroscopic measurements and data processing associated with previous electrochemical ${ }^{20,29,41}$ and electrogravimetric measurements $7,8,21,23,24,39,40$ that allowed the counterions exchanged during this scan to be distinguished according to the applied potential. Previous structural results ${ }^{33,34}$ allowed the electroactive Fe sites to be specified. Furthermore, this paper suggests a molecular first approximation to a better understanding of the electronic dynamics of PB films during their voltammetric scan.

\section{Experimental}

PB films were electrochemically deposited by immersion in $0.02 \mathrm{M} \mathrm{K}_{3} \mathrm{Fe}(\mathrm{CN})_{6}$ [analytical reagent (AR), Panreac], $0.02 \mathrm{M}$ $\mathrm{FeCl}_{3}$ (Sigma), and $0.01 \mathrm{M} \mathrm{HCl}$ (AR, R. P. Normapur) solution. ${ }^{22} \mathrm{~A}$ controlled cathodic current density of $40 \mu \mathrm{A} \mathrm{cm}^{-2}$ was applied for $150 \mathrm{~s}$. Next, these PB films were stabilized by cycling the system between 0.60 and $-0.20 \mathrm{~V}$ in $0.50 \mathrm{M} \mathrm{KCl}, \mathrm{pH} 2.3^{30,42}$

Spectroelectrochemical measurements were carried out in a typical electrochemical three-electrode cell. PB films were deposited on an ITO (indium tin oxide) electrode with a covering surface of $1 \mathrm{~cm}^{2}$ (the ohmic drop of ITO electrodes causes the separation and widening of voltammetric peaks). ${ }^{43,44}$ A platinum plate was used as the counter electrode and an $\mathrm{Ag}|\mathrm{AgCl}| \mathrm{KCl}_{\text {sat }}$ electrode was used as the reference electrode. A PalmSens potentiostat (Palm Instrument BV) controlled the electrochemical measurements realized at steady-state conditions. These measurements were performed by using the spectral range given by a HEגIOS $\beta$ UV-visible (UV-vis) spectroscope (Spectronic Unicam) (Fig. 1). Potential changes during the voltammetric measurements were modulated through a PAR 263A potentiostat-galvanostat, whereas spectroscopic measurements during this cycle were realized in situ by a Jenway 6300 spectrophotometer (Fig. 2). The electrolyte used in all experiments was $0.50 \mathrm{M} \mathrm{KCl}$ (AR, R. P. Normapurtm), pH 2.3. Study of the anodic scan is obviated here to make the analysis of the experimental results easier. However, this scan totally agrees with conclusions obtained from the cathodic scan due to the reversibility of the $\mathrm{PB} \rightleftarrows \mathrm{ES}$ voltammetric scan. 


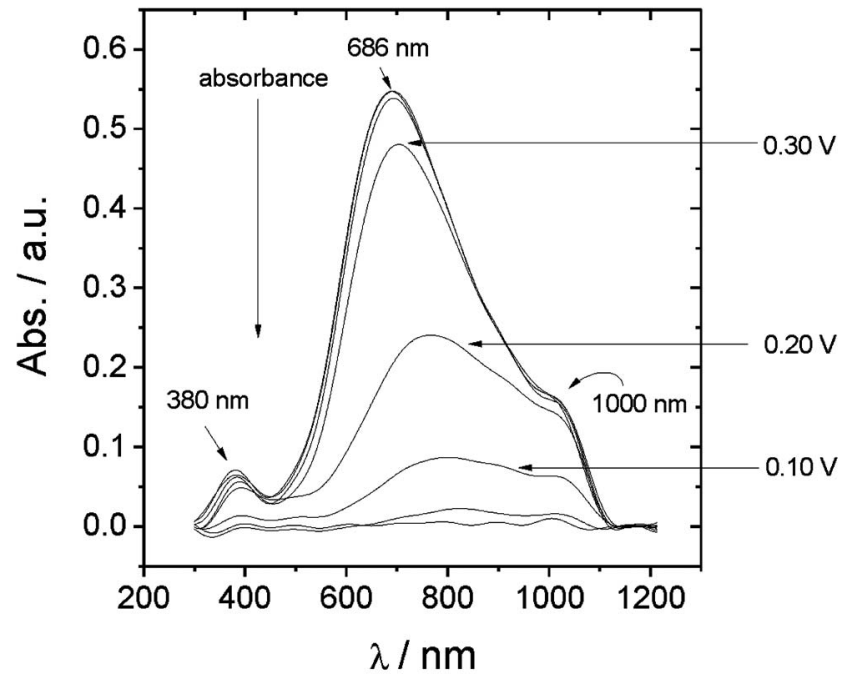

Figure 1. Near-UV-vis/near-IR absorbance spectra of PB films on ITO electrodes at different polarization potentials in the potential range between 0.60 and $-0.20 \mathrm{~V}$ (vs $\mathrm{Ag} / \mathrm{AgCl} / \mathrm{KCl}_{\text {sat }}$ ). The spectra shown are spaced at $0.10 \mathrm{~V}$. The electrolyte was $0.50 \mathrm{M} \mathrm{KCl}, \mathrm{pH} 2.3$.

\section{Results and Discussion}

Spectroscopic analysis. - The near-UV-vis/near-IR spectrum of PB films shows two spectroscopic bands centered at 380 and $686 \mathrm{~nm}$, as well as a shoulder at $1000 \mathrm{~nm}$ (see Fig. 1). The spectroscopic band centered at $686 \mathrm{~nm}$ records the electronic charge transfer from iron(II) into low-spin sites to iron(III) ions into high-spin sites. ${ }^{35}$ Thus, absorbance changes at this wavelength may be related to the amount of $\mathrm{Fe}(\mathrm{II})_{\text {low-spin }}-\mathrm{CN}-\mathrm{Fe}(\mathrm{III})_{\text {high-spin }}$ sites. The shoulder at $1000 \mathrm{~nm}$ records a forbidden transition of the above charge transfer. The spectroscopic band detected at $380 \mathrm{~nm}$ records the electronic charge transfer from iron(II) ions into high-spin sites to iron(III) ions into low-spin sites. Changes of this band are related to the amount of $\mathrm{Fe}(\mathrm{III})_{\text {low-spin }}-\mathrm{CN}-\mathrm{Fe}(\mathrm{II})_{\text {high-spin }}$ sites. $^{35}$

Figure 1 shows absorbance changes during the electrochemical transition between the PB $(0.60 \mathrm{~V})$ and ES $(-0.20 \mathrm{~V})$ forms. The spectral intensities of the near-UV-vis/near-IR spectrum of a PB film decrease during this transition due to the decrease of the amount of

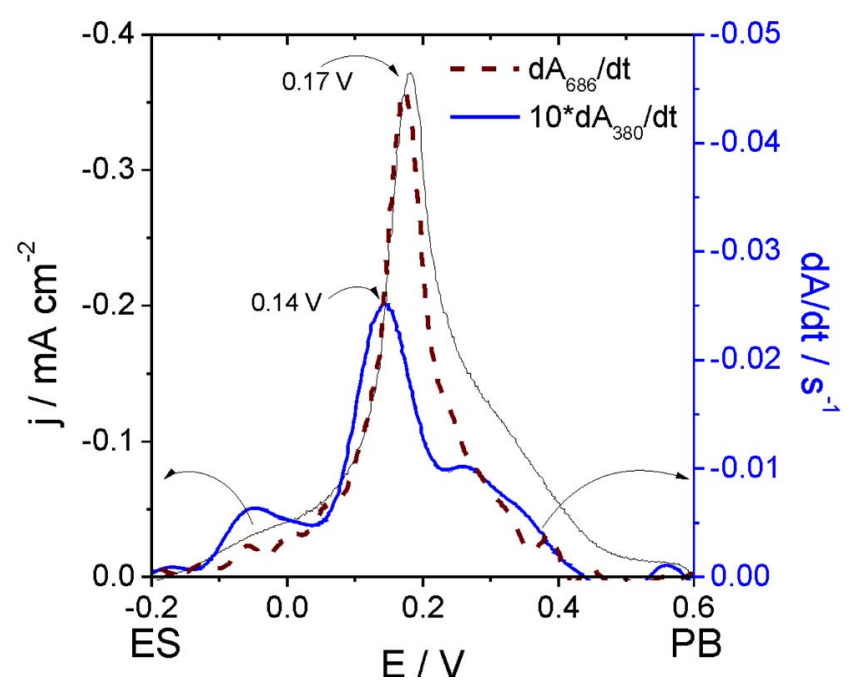

Figure 2. (Color online) The derivative of the voltabsommetric scan and the voltammetric scan between the PB $(0.60 \mathrm{~V})$ and ES $(-0.20 \mathrm{~V})$ forms at $10 \mathrm{mV} / \mathrm{s}$. The electrolyte was $0.50 \mathrm{M} \mathrm{KCl}, \mathrm{pH} 2.3$. chromophore sites caused by the reduction of the trivalent iron ions by two processes. The electrochemical reaction monitored at $686 \mathrm{~nm}$ could be summarized as

$$
\begin{aligned}
& \mathrm{Fe}(\mathrm{II})_{\text {low-spin }}-\mathrm{CN}-\left.\mathrm{Fe}(\mathrm{III})_{\text {high-spin }}\right|_{\text {signal at }} 686 \mathrm{~nm}(\mathrm{~PB})+1 \mathrm{e}^{-}+\text {cation } \\
& \quad \rightarrow \mathrm{Fe}(\mathrm{II})_{\text {low-spin }}-\mathrm{CN}-\left.\mathrm{Fe}(\mathrm{II})_{\text {high-spin }}(\text { cation })\right|_{\text {nonsignal at } 686 \mathrm{~nm}}(\mathrm{ES})
\end{aligned}
$$

whereas the electrochemical reaction monitored at $380 \mathrm{~nm}$ should be

$$
\begin{aligned}
& \mathrm{Fe}(\mathrm{III})_{\text {low-spin }}-\mathrm{CN}-\left.\mathrm{Fe}(\mathrm{II})_{\text {high-spin }}\right|_{\text {signal at }} 380 \mathrm{~nm}(\mathrm{~PB})+1 \mathrm{e}^{-}+\text {cation } \\
& \quad \rightarrow \mathrm{Fe}(\mathrm{II})_{\text {low-spin }}(\text { cation })-\mathrm{CN}-\left.\mathrm{Fe}(\mathrm{II})_{\text {high-spin }}\right|_{\text {nonsignal at } 380 \mathrm{~nm}}(\mathrm{ES})
\end{aligned}
$$

In spite of the fact that near-UV-vis/near-IR spectra of PB films present three spectral transitions at 686, 380, and $1000 \mathrm{~nm}$, only the spectroscopic bands centered at 686 and $380 \mathrm{~nm}$ are well-defined (Fig. 1). As commented above, these bands allow $\mathrm{Fe}(\mathrm{II})_{\text {low-spin }}{ }^{-}$ $\mathrm{CN}-\mathrm{Fe}(\mathrm{III})_{\text {high-spin }}$ and $\mathrm{Fe}(\mathrm{III})_{\text {low-spin }}-\mathrm{CN}-\mathrm{Fe}(\mathrm{II})_{\text {high-spin }}$ electroactive sites to be monitored during the $\mathrm{PB} \rightleftarrows \mathrm{ES}$ voltammetric scan. It is important to indicate that counterions of electrochemical reactions of PB films interact with the crystalline structure into a specific structural site ${ }^{21}$ and as a result, the electrochemical reaction of each chromophore or each electroactive site may involve only a counterion having appropriate dimensions to fill these sites.

Figure 2 shows that the derivative of the voltabsommetric curves $(d A / d t)$ at 686 and $380 \mathrm{~nm}$ have a maximum at 0.17 and $0.14 \mathrm{~V}$, respectively. Previous electrogravimetric measurements ${ }^{21,29}$ have shown that the counterions exchanged in this potential range for reaching the film electroneutrality are mainly potassium ions added to a few hydrated protons. As the derivative of the voltabsommetric scan at $686 \mathrm{~nm}$ is clearly coupled to the cathodic voltammetric scan, it can be inferred that this wavelength is related to the exchange of potassium ions as counterions. The counterion associated with the $380 \mathrm{~nm}$ wavelength would be the hydrated proton given that the electrochemical reaction of $\mathrm{Fe}(\mathrm{II})_{\text {low-spin }}-\mathrm{CN}-\mathrm{Fe}(\mathrm{III})_{\text {high-spin }}$ sites is related to the potassium counterion and that each electroactive $\mathrm{Fe}$ site may involve only a counterion. ${ }^{21}$ Furthermore, this is in accordance with the fact that the absorbance at this wavelength is smaller than the absorbance at $686 \mathrm{~nm}$ (Fig. 1).

As the values of absorbance at 686 and $380 \mathrm{~nm}$ are related to $\mathrm{Fe}(\mathrm{II})_{\text {low-spin }}-\mathrm{CN}-\mathrm{Fe}(\mathrm{III})_{\text {high-spin }}$ and $\mathrm{Fe}(\mathrm{III})_{\text {low-spin }}-\mathrm{CN}-$ $\mathrm{Fe}(\mathrm{II})_{\text {high-spin }}$ sites, respectively, it is possible to write the electrochemical reduction reactions

$$
\begin{gathered}
\mathrm{Fe}(\mathrm{II})_{\text {low-spin }}-\mathrm{CN}-\mathrm{Fe}(\mathrm{III})_{\text {high-spin }}+\mathrm{K}^{+} \\
\stackrel{1 \mathrm{e}^{-}}{\longrightarrow} \mathrm{Fe}(\mathrm{II})_{\text {low-spin }}-\mathrm{CN}-\mathrm{Fe}(\mathrm{II})_{\text {high-spin }}\left(\mathrm{K}^{+}\right) \\
\mathrm{Fe}(\mathrm{III})_{\text {low-spin }}-\mathrm{CN}-\mathrm{Fe}(\mathrm{II})_{\text {high-spin }}+\mathrm{H}_{3} \mathrm{O}^{+} \\
\stackrel{1 \mathrm{e}^{-}}{\longrightarrow} \mathrm{Fe}(\mathrm{II})_{\text {low-spin }}\left(\mathrm{H}_{3} \mathrm{O}^{+}\right)-\mathrm{CN}-\mathrm{Fe}(\mathrm{II})_{\text {high-spin }}
\end{gathered}
$$

Voltammetric simulation from the derivative of the voltabsommetric scans.- One of the most interesting possibilities of spectroelectrochemistry is that it provides a good starting point to deconvoluted electrochemical processes. If the molar extinction coefficients are known at each wavelength, the current associated to each one of these processes could be estimated from Beer-Lambert and Faraday's laws. ${ }^{45,46}$ If

$$
j_{\text {total }}=\sum_{n} \frac{d Q_{n} \text { Faraday's law }}{d t}=F \sum_{n} \frac{d(\mathrm{~mol})_{n}}{d t}=F V \sum_{n} \frac{d C_{n}}{d t}
$$

and as 


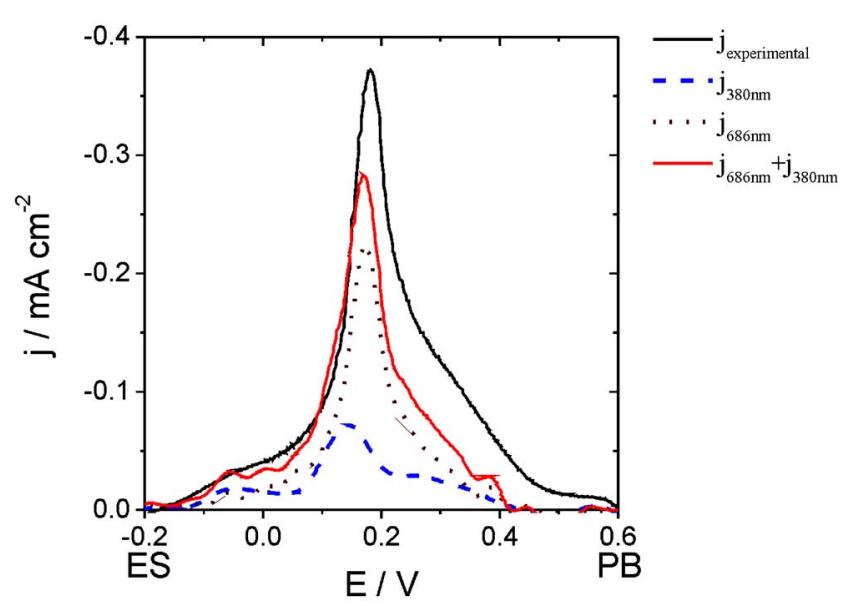

Figure 3. (Color online) Simulated and experimental voltammetric scan between the PB $(0.60 \mathrm{~V})$ and ES $(-0.20 \mathrm{~V})$ forms at $10 \mathrm{mV} / \mathrm{s}$. The voltammetric simulation was realized from Eq. $5 \mathrm{c}$, considering that $\left.(\varepsilon / S F)\right|_{380}$ $=35 \mathrm{C}^{-1}$ and $\left.(\varepsilon / S F)\right|_{686}=200 \mathrm{C}^{-1}$. The electrolyte was $0.50 \mathrm{M} \mathrm{KCl}, \mathrm{pH}$ 2.3 .

$$
\frac{d A_{n}}{d t}=l \varepsilon_{n} \frac{d C_{n}}{d t}
$$

then

$$
j_{\text {total }}=\sum_{n} \frac{S l F}{l \varepsilon_{n}} \frac{d A_{n}}{d t}=\sum_{n} \frac{S F}{\varepsilon_{n}} \frac{d A_{n}}{d t}
$$

where $A$ is the absorbance of the sample, $l$ is the distance that light travels through the material (the path length), $C_{n}$ is the concentration of chromophore $n,(\mathrm{~mol})_{n}$ are the moles related to the concentration $C_{n}, \varepsilon_{n}$ is the molar extinction coefficient of the absorber $n, V$ is the material volume, $S$ is the surface of the absorber, $F$ is the Faraday constant, $t$ is time, and $Q_{n}$ is the electrical charge associated with the absorber $n . j_{\text {total }}$ is the total current density at each polarization potential.

As each electroactive site has been associated with only one chromophore exchanging only one specific counterion, the highest value of the $F d A / d Q$ function, $F d A / d Q=F(d A / d t) / i$ $=F(d A / d t) /(d Q / d t)$, can be used as a first estimate of the extinction coefficient of absorber per surface at each wavelength. However, the true coefficient should be larger than the highest value of the $F d A / d Q$ function, because at each polarization potential, more than one electrochemical process that gives current change coexists and only one gives absorbance change. ${ }^{45-47}$ Figure 3 shows the simulation of the cathodic voltammetric scan from $d A / d t$ curves at 380 and $686 \mathrm{~nm}$ and Eq. 5c. The iterative method of simulation was initialized by means of the coefficients obtained from the maximum of the $F d A / d Q$ functions, $\left.(\varepsilon / S F)\right|_{380}=13 \mathrm{C}^{-1}$ and $\left.(\varepsilon / S F)\right|_{686}$ $=128 \mathrm{C}^{-1}$. The reached optimal values were $\left.(\varepsilon / S F)\right|_{380}=35 \mathrm{C}^{-1}$ and $\left.(\varepsilon / S F)\right|_{686}=200 \mathrm{C}^{-1}$.

It can be seen in Fig. 3 that experimental current agrees with simulated curves at potentials between -0.20 and $0.15 \mathrm{~V}$. However, differences are important at more anodic potentials and unquestionably, they cannot be rectified given that minimum values of the molar extinction coefficients were considered by an experimental determination from the $F d A / d Q$ function. Thus, as the electrochemical reactions of $\mathrm{Fe}(\mathrm{II})_{\text {low-spin }}-\mathrm{CN}-\mathrm{Fe}(\mathrm{III})_{\text {high-spin }}$ and $\mathrm{Fe}(\mathrm{III})_{\text {low-spin }}-\mathrm{CN}-\mathrm{Fe}(\mathrm{II})_{\text {high-spin }}$ sites occur mainly at potentials lower than $0.15 \mathrm{~V}$, other electrochemical reactions may be involved at more anodic potentials. Figure 3 also shows that the main reaction near the peak potential is related to the current density deconvoluted from the $d A / d t$ curve at $686 \mathrm{~nm}$. Thus, this is in concordance with the fact that the electrochemical reaction of $\mathrm{Fe}(\mathrm{II})_{\text {low-spin }}-\mathrm{CN}-$

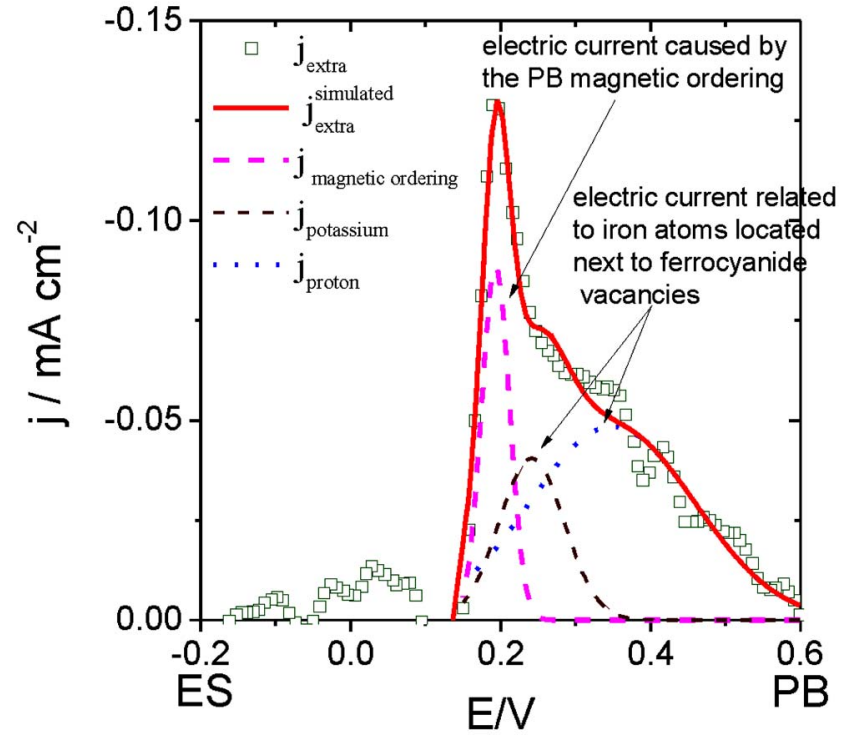

Figure 4. (Color online) Simulation of $j_{\text {extra. Simulation parameters }}$ are $\quad j_{\mathrm{K}^{+}}=-4.4 \times 10^{-6} / 0.087 \sqrt{\pi / 2} e^{-2[(E-0.241) / 0.087]^{2}}, \quad j_{\text {magnetic }}=-4.1$ $\times 10^{-6} / 0.037 \sqrt{\pi / 2} e^{-2[(E-0.193) / 0.037]^{2}}, \quad j_{\mathrm{H}^{+}}=-1.0 \times 10^{-5} / 0.220 \sqrt{\pi / 2}$ $\times e^{-2[(E-0.350) / 0.220]^{2}}$.

$\mathrm{Fe}(\mathrm{III})_{\text {high-spin }}$ sites that is monitored at $686 \mathrm{~nm}$ involve the potassium counterion for reaching the film electroneutrality, because the electrochemical reaction that involves the exchange of potassium cations is the main reaction at these potentials. ${ }^{21,29}$

An extra current density can be defined as the difference between the experimental and simulated currents, $j_{\text {extra }}$

$$
j_{\text {total }}=\frac{S F}{\varepsilon_{686}} \frac{d A_{686}}{d t}+\frac{S F}{\varepsilon_{380}} \frac{d A_{380}}{d t}+j_{\text {extra }}
$$

Figure 4 shows the shape of this extra current. This shape does not correspond to only one process; it seems to be due to the overlapping of at least three different processes. To separate these three contributions to the extra current, it can be deconvoluted into three different Gaussian peaks. This methodology is usually employed in many scientific fields. ${ }^{48}$ In this case, Gaussian functions can be used to simulate electrochemical processes, given that they have the same shape as a voltammetric peak, which is usually simulated from hyperbolic cosine functions. ${ }^{47}$ Following this procedure, the deconvolution of $j_{\text {extra }}$ gives three peaks with a high overlapping degree and centered at $0.20,0.25$, and $0.35 \mathrm{~V}$ (Fig. 4). Three processes is the minimum needed to obtain a good deconvolution.

At potentials near $0.20 \mathrm{~V}$ (the voltammetric peak potential), the experimental voltammogram shows a high and narrow peak. The cause of this narrow peak has been related to a PB magnetostructural changeover process which causes an extra nonfaradaic current, ${ }^{7,8,44}$ as well as to a faradaic process that involves the potassium exchange and that can be recorded by the wavelength at $686 \mathrm{~nm}$, as commented above. At potentials near $0.25 \mathrm{~V}$, the main faradaic reaction involves the exchange of potassium counterions and that causes neither changes of absorbance at $686 \mathrm{~nm}$ nor at $380 \mathrm{~nm}$. Finally, previous electrogravimetric measurements evidenced the participation of protons as counterions at more anodic potentials than $0.30 \mathrm{~V} .^{21}$ Thus, and as these potentials agree with the potentials of the deconvoluted currents in Fig. 4, these processes may be related. Thus, the Gaussian peak centered at $0.20 \mathrm{~V}$ may be related to the extra nonfaradaic current, the peak at 0.25 to the potassium exchange, and the peak at $0.35 \mathrm{~V}$ to the proton exchange. Potassium counterions are so related to two different faradaic reactions. 


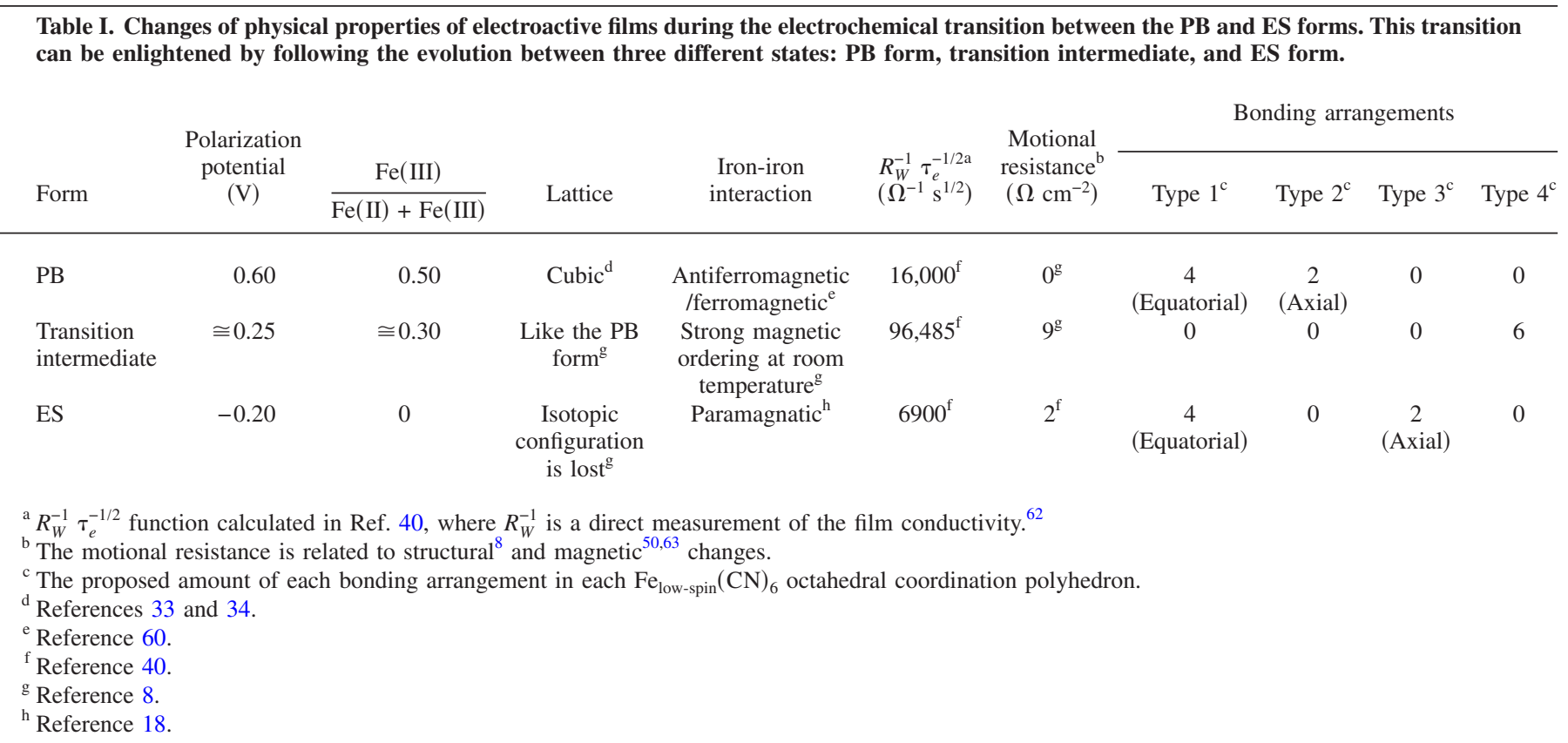

The role of electroactive Fe sites located next to ferrocyanide vacancies. - It is well-known that trivalent iron ions are responsible for $\mathrm{PB}$ electrochemical reactions. These ions are mainly located in $\mathrm{Fe}(\mathrm{II})_{\text {low-spin }}-\mathrm{CN}-\mathrm{Fe}(\mathrm{III})_{\text {high-spin }}$ and $\mathrm{Fe}(\mathrm{III})_{\text {low-spin }}-\mathrm{CN}-$ $\mathrm{Fe}(\mathrm{II})_{\text {high-spin }}$ sites. Furthermore, these ions are also located next to ferrocyanide vacancies in two possible electroactive $\mathrm{Fe}$ sites, depending on the $\mathrm{pH}$ and experimental conditions: ${ }^{21,26,34}$ $\mathrm{Fe}^{3+}(\mathrm{NC})_{5} \mathrm{OH}_{2}$ (two sites for each vacancy) and $\mathrm{Fe}^{3+}(\mathrm{NC})_{5} \mathrm{OH}^{-}$ (four sites for each vacancy).

As commented above, electrochemical reactions of trivalent iron ions located in $\mathrm{Fe}(\mathrm{II})_{\text {low-spin }}-\mathrm{CN}-\mathrm{Fe}(\mathrm{III})_{\text {high-spin }}$ and $\mathrm{Fe}(\mathrm{III})_{\text {low-spin }}-\mathrm{CN}-\mathrm{Fe}(\mathrm{II})_{\text {high-spin }}$ chromophore sites can be monitored from the spectroscopic bands centered at 686 and $380 \mathrm{~nm}$, respectively. Therefore, and as the processes associated with $j_{\text {extra }}$ does not cause absorbance changes, $j_{\text {extra }}$ may be related to the electrochemical reactions of the $\mathrm{Fe}^{3+}(\mathrm{NC})_{5} \mathrm{OH}_{2}$ and $\mathrm{Fe}^{3+}(\mathrm{NC})_{5} \mathrm{OH}^{-}$ electroactive $\mathrm{Fe}$ sites located next to ferrocyanide vacancies of the $\mathrm{PB}$ structure. In agreement with this, $\mathrm{Fe}^{2+}(\mathrm{CN})_{5} \mathrm{H}_{2} \mathrm{O}$ complexes are electroactive in aqueous solution between 0.40 and $0.70 \mathrm{~V},{ }^{49}$ where Fig. 4 shows that $j_{\text {extra }}$ is mainly recorded, and in the same manner as the extra current density calculated above, these complexes do not absorb in the near-UV-vis/near-IR range. ${ }^{49}$

Figure 4 shows that the deconvoluted peak centered at $0.35 \mathrm{~V}$ (which is shown above to be related to the exchange of proton counterions) has a double transferred electric charge than the charge of the deconvoluted peak centered at $0.25 \mathrm{~V}$ (which is related above to the exchange of potassium counterions). This should indicate that there are double the electroactive sites corresponding to the deconvoluted peak centered at $0.35 \mathrm{~V}$ than sites corresponding to the deconvoluted peak centered at $0.25 \mathrm{~V}$. Therefore, as there are also the double of $\mathrm{Fe}^{3+}(\mathrm{NC})_{5} \mathrm{OH}^{-}$sites than $\mathrm{Fe}^{3+}(\mathrm{NC})_{5} \mathrm{OH}_{2}$ sites, ${ }^{21,26,34}$ it is possible to say that the electrochemical reaction of $\mathrm{Fe}^{3+}(\mathrm{NC})_{5} \mathrm{OH}_{2}$ sites should involve the potassium counterion, whereas the electrochemical reaction that involves the proton counterion should correspond to $\mathrm{Fe}^{3+}(\mathrm{NC}){ }_{5} \mathrm{OH}^{-}$sites.

From the aforesaid results, electrochemical reduction reactions of iron ions located next to ferrocyanide vacancies could be written as

$$
\mathrm{Fe}^{3+}(\mathrm{NC})_{5} \mathrm{OH}_{2}+\mathrm{K}^{+} \stackrel{1 \mathrm{e}^{-}}{\longrightarrow} \mathrm{Fe}^{2+}(\mathrm{NC})_{5} \mathrm{OH}_{2}\left(\mathrm{~K}^{+}\right)
$$

$$
\mathrm{Fe}^{3+}(\mathrm{NC})_{5} \mathrm{OH}^{-}+\mathrm{H}^{+} \stackrel{1 \mathrm{e}^{-}}{\longrightarrow} \mathrm{Fe}^{2+}(\mathrm{NC})_{5} \mathrm{OH}_{2}
$$

In view of that, there are two different electrochemical reactions associated with potassium counterions: the reaction of $\mathrm{Fe}(\mathrm{II})_{\text {low-spin }}-\mathrm{CN}-\mathrm{Fe}(\mathrm{III})_{\text {high-spin }}$ sites and the reaction of $\mathrm{Fe}^{3+}(\mathrm{NC})_{5} \mathrm{OH}_{2}$ sites. This is consistent with the double role of potassium cations during the $\mathrm{PB} \rightleftarrows \mathrm{ES}$ scan. ${ }^{24,31}$

Finally, Fig. 4 shows how the electric current caused by the PB changeover (which is characterized by the presence of an internal magnetic field induced $\left.{ }^{8,50}\right)$ during their voltammetric scan is observed when almost all $\mathrm{Fe}^{3+}(\mathrm{NC})_{5} \mathrm{OH}^{-}$and $\mathrm{Fe}^{3+}(\mathrm{NC})_{5} \mathrm{OH}_{2}$ sites are reduced. Conversely, the electrochemical reduction reactions of $\mathrm{Fe}(\mathrm{II})_{\text {low-spin }}-\mathrm{CN}-\mathrm{Fe}(\mathrm{IIII})_{\text {high-spin }}$ and $\mathrm{Fe}(\mathrm{III})_{\text {low-spin }}-\mathrm{CN}-$ $\mathrm{Fe}(\mathrm{II})_{\text {high-spin }}$ sites occur mainly at more cathodic potentials. Therefore, it is possible to say that the reduction of all Fe sites located next to ferrocyanide vacancies should cause the PB magnetostructural changeover at room temperature. In agreement with this, previous experimental studies in other similar materials showed that the presence of vacancies is a prerequisite for photomagnetism. ${ }^{51,52}$ Furthermore, this agrees with the observed fact that the photomagnetism of $\mathrm{CoFe} \mathrm{PB}$ analog depends on the amount of ferrocyanide vacancies and on the nature of alkali cations ${ }^{53}$ (i.e., potassium) per cell. This could be explained considering that electrochemical processes related to $\mathrm{Fe}$ sites located next to ferrocyanide vacancies $\left[\mathrm{Fe}^{3+}(\mathrm{NC})_{5} \mathrm{OH}_{2}\right.$ sites $]$ involve potassium counterions for reaching the film electroneutrality.

A molecular perspective on $P B$ films during their voltammetric scan.- As commented above, an electric current induced by the PB magnetic ordering was detected during their voltammetric scan. This current is due to a changeover for a $\mathrm{Fe}(\mathrm{III}) /[\mathrm{Fe}$ (II) $+\mathrm{Fe}(\mathrm{III})]$ ratio of about $0.30,{ }^{7,8}$ as is described in Table I. This changeover causes reversible changes on physical properties of films (i.e., structural, electrical, optical magnetic, and negative magnetoresistive effects), ${ }^{8-10,50}$ which begins the appearance of a nonfaradaic current. The origin of these changes has not been clarified yet, especially those concerning the interaction between iron ions, ferrocyanide vacancies, and counterions. Accordingly, the following section suggests a molecular first approximation to a better understanding of the 
dynamics of this changeover process. Herein, the proposed approach to explain the origin of reversible changes on physical properties of PB films during the voltammetric scan is based on the covalentexchange model, ${ }^{54}$ which is supported by the fact that changes in these films depend on the interaction between neighboring iron ions mediated by cyanide bonds. ${ }^{55}$ The superexchange model could also be used. However, the system should be ferromagnetic for all $\mathrm{Fe}$ (III) compositional fractions considering this last model. ${ }^{54}$ Therefore, as the ES form has paramagnetic features, ${ }^{18}$ this possibility can be rejected.

According to the covalent-exchange model, the $\mathrm{Fe}_{\text {low-spin }}{ }^{-}$ $\mathrm{CN}-\mathrm{Fe}_{\text {high-spin }}$ chain units have four possible bonding arrangements, all of them depending on the level of covalent strength of the $\mathrm{Fe}_{\text {low-spin }}-\mathrm{CN}$ or $\mathrm{CN}-\mathrm{Fe}_{\text {high-spin }}$ bonds: ${ }^{54}$

1. The type 1 bonding arrangement occurs when these two types of bonds have a high covalent character. In this way, the iron ions are weakly coupled antiferromagnetically below the Curie temperature.

2. The type 2 bonding arrangement occurs when only one of these bonds has a high covalent character whereas the other has an ionic character. Considering the latter picture, the cyanide ligands are displaced toward the covalently iron-bonded atom and the net magnetic moment of this arrangement is ferromagnetic.

3 . In the type 3 bonding arrangement, the two bonds have a high ionic character and as a result, there is nonmagnetic exchange between neighboring iron ions.

4. The type 4 bonding arrangement is reached when the lattice has a random ordering of oxidation states. In this arrangement, the $\mathrm{Fe}(\mathrm{II})_{\text {low-spin }}-\mathrm{CN}-\mathrm{Fe}(\mathrm{III})_{\text {high-spin }}$ state is degenerated regarding the $\mathrm{Fe}(\mathrm{III})_{\text {low-spin }}-\mathrm{CN}-\mathrm{Fe}(\mathrm{II})_{\text {high-spin }}$ state in a way that ferromagnetic double exchange takes place between iron ions below the Curie temperature. ${ }^{56}$ Therefore, one electron is free to move through a metallic-like bond. Low electrical resistivity and small iron-iron distances are associated with this double-exchange phenomenon.

Considering these bonding arrangements, the electrochemical transition between the PB and ES forms can be characterized by following the evolution between three different states characterized by the value of $\alpha=\mathrm{Fe}(\mathrm{III}) /[\mathrm{Fe}(\mathrm{II})+\mathrm{Fe}(\mathrm{III})]$ : $\mathrm{PB}$ form $(\alpha=0.50$, at $0.60 \mathrm{~V})$, transition intermediate $(\alpha \cong 0.30$, at about $-0.25 \mathrm{~V})$, and ES form $(\alpha=0$, at $-0.20 \mathrm{~V})$, where fewer and fewer Fe(III) ions are involved.

The PB form is mainly a mixed valence system of $\mathrm{Fe}(\mathrm{II})_{\text {low-spin }}-\mathrm{CN}-\mathrm{Fe}(\mathrm{III})_{\text {high-spin }}$ units with different bonding arrangements. $^{35}$ Recent studies ${ }^{33,34}$ indicated that the $\mathrm{Fe}(\mathrm{II})_{\text {low-spin }}-\mathrm{CN}$ mean length is equivalent to $2.00 \AA$, whereas the $\mathrm{CN}-\mathrm{Fe}(\mathrm{IIII})_{\text {high-spin }}$ mean length is equal to $1.92 \AA$. Accordingly, and considering that the geometry of ferrocyanide anions is octahedral slightly distorted, ${ }^{57} 4 / 6$ of bonding arrangements may correspond to the type 1 arrangement whereas $2 / 6$ of bonding arrangements may correspond to the type 2 , in which $\mathrm{Fe}(\mathrm{II})_{\text {low-spin }}-\mathrm{CN}$ bonds have a high ionic character. Thus, all $\mathrm{CN}-\mathrm{Fe}_{\text {high-spin }}$ bonds have a high covalent nature and therefore, axial cyanide ligand groups of the $\mathrm{Fe}_{\text {low-spin }}(\mathrm{CN})_{6}$ octahedral coordination polyhedron would be largely displaced toward $\mathrm{Fe}_{\text {high-spin }}$ ions, as detected experimentally. ${ }^{33,34}$

The ordering of type 1 bonding arrangements within $(h 00)$ planes and of all type 2 bonding arrangements between these planes is the best ordering to minimize the cooperative elastic strain due to the presence of two bonding arrangements. ${ }^{54}$ For this reason, this ordering may be the conformation that the PB form reaches. Such ordering provides an optimum electrostatic configuration as well as a cooperative elastic strain capable to keep the cubic symmetry, as was assumed for the PB structure. ${ }^{33,34}$ The type 2 bonding arrangement entails the ferromagnetic features of the PB material, already shown for PB-like materials. ${ }^{58,59}$ The type 1 bonding arrangement also agrees with the magnetic anisotropy that gives rise to weak antiferromagnetic/ferromagnetic interactions in $\mathrm{PB}$ analog materials. ${ }^{60}$ Furthermore, both arrangements imply a high electrical

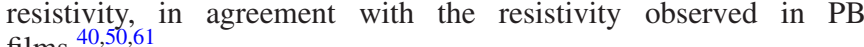
films. ${ }^{40,50,61}$

An important increase in the exchange integral between iron ions located in high- and low-spin sites has recently been detected during the $\mathrm{PB} \rightleftarrows \mathrm{ES}$ scan when the system reaches a $\alpha \cong 0.30$, implying the optimization of double-exchange efficiency at this fractional content. ${ }^{50}$ As a result, the $\mathrm{Fe}(\mathrm{III}) /[\mathrm{Fe}(\mathrm{II})+\mathrm{Fe}(\mathrm{III})]$ ratio around 0.30 leads to the easier electronic exchange between neighboring iron ions. If the covalent-exchange model should be considered as an appropriated model, then an abrupt change (due to optimization of double-exchange efficiency) of this exchange integral would be expected for $\alpha$ around $0.31,{ }^{54}$ thus supporting the use of this model to explain the behavior of the PB films during their voltammetric scan. Furthermore, and as this theoretic model establishes, the different PB electronic conformations shown in Table I imply the cooperative modification of the bonds of iron ions because the change of the film conductivity during the transition between the PB and ES forms is very important.

Accordingly, and if the optimized efficiency of double-exchange mechanism in PB materials around 0.30-0.32 $\alpha$ compositions is considered, then $\mathrm{Fe}_{\text {low-spin }}-\mathrm{CN}-\mathrm{Fe}_{\text {high-spin }}$ structural units may have only a type 4 bonding arrangement at this compositional ratio, because the double-exchange efficiency is reduced by electrostatic ordering. ${ }^{56}$ This isotropic arrangement would imply that the crystalline framework is cubic similarly to the PB form. Thus, this picture explains the observed changeover process, i.e., why the film's structure only changes from this specific composition. ${ }^{7,8}$ The type 4 bonding arrangement, caused by the double-exchange optimized feature,${ }^{54}$ has an important ferromagnetic coupling and a relatively high electric conductivity, ${ }^{56}$ already demonstrated for this material at this compositional ratio $8,40,50$ (see Table I).

Finally, the ES form is composed of only divalent iron ions into high- and low-spin sites where the octahedral geometry of the ferrocyanide anions is slightly distorted, ${ }^{56}$ similar to that found in the PB form. Furthermore, Fe(II) $)_{\text {low-spin }}$ (high-spin $\mathrm{d}^{6}$ configuration) ions are weakly Jahn-Teller active. ${ }^{64}$ The Jahn-Teller effect, sometimes also known as Jahn-Teller distortion, describes the geometrical distortion of nonlinear molecules under certain situations. This distortion normally takes the form of elongating the bonds to the ligands lying along the $z$ axis. Hence, 4/6 of iron-ligand bonds (the four equatorial octahedral coordinated groups of $\mathrm{Fe}_{\text {low-spin }}(\mathrm{CN})_{6}$ and $(\mathrm{CN})_{6} \mathrm{Fe}_{\text {high-spin }}$ polyhedrons) have high covalent character, whereas $2 / 6$ of iron-ligand bonds (the two axial octahedral coordinated groups of $\mathrm{Fe}_{\text {low-spin }}(\mathrm{CN})_{6}$ and $(\mathrm{CN})_{6} \mathrm{Fe}_{\text {high-spin }}$ polyhedrons) have high ionic character.

One possible arrangement of the mentioned bonds is a coplanar ordering of all similar bonds in $(h 00)$ planes. This PB bond ordering is highly probable because it minimizes the cooperative elastic strain by elongating the bonds along the $z$ axis. In such an arrangement, $\mathrm{Fe}(\mathrm{II})_{\text {low-spin }}-\mathrm{CN}-\mathrm{Fe}(\mathrm{II})_{\text {high-spin }}$ bonds within $(h 00)$ planes may correspond to the type 1 bonding arrangement, whereas bonds between these planes would correspond to the type 3 bonding arrangement; the ES and PB conformations may then be different in axial octahedral coordinated bonds of $(\mathrm{CN})_{6} \mathrm{Fe}_{\text {high-spin }}$ polyhedrons (see Table I). This conformation may produce an anisotropic configuration. Therefore, the rigid isotropic framework is lost according to what was discussed for the ES form in a previous paper. ${ }^{8}$ Furthermore, the high electrical resistivity that has been observed in ES films confirms the above statement. ${ }^{29,40}$ The proposed conformation leads to the presence of antiferromagnetic properties along $(h 00)$ planes and paramagnetic properties along $(0 \mathrm{k} 0)$ planes. The paramagnetic character of the ES structure is corroborated in the reduced state of $\mathrm{PB}$ analogs. ${ }^{18}$

The present work shows that the experimental evolution of physical properties of electroactive films during the electrochemical transition between the PB and ES forms is consistent with the covalent-exchange model. Actually, this model shows that the electrochemical transition of the PB and ES forms can be explained by 


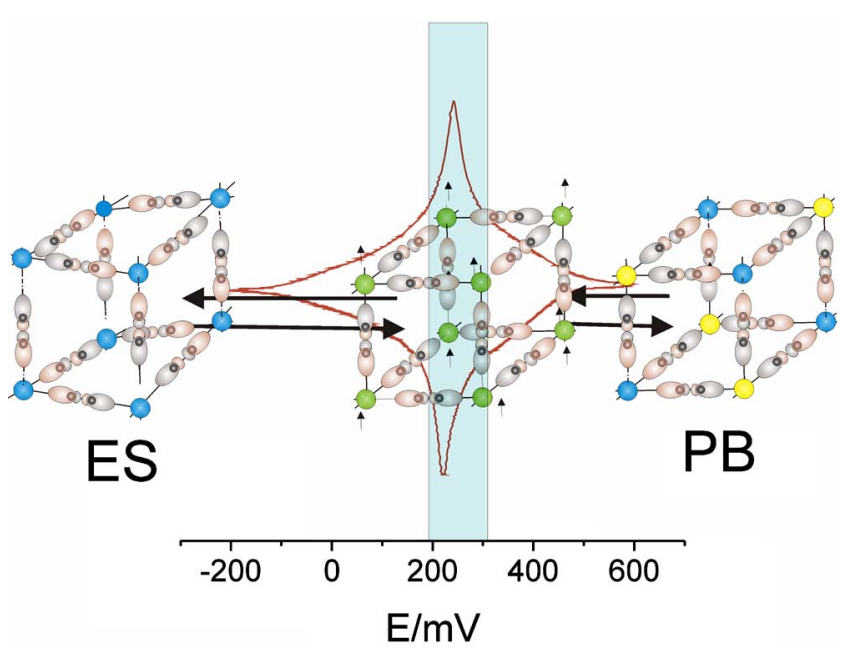

Figure 5. (Color online) Schematic configuration of the evolution of an octant of the unit cell during the electrochemical transition between the PB and ES forms, according to the covalent-exchange model. Blue balls ( correspond to $\mathrm{Fe}(\mathrm{II})$ ions, yellow balls $(\mathrm{O})$ to $\mathrm{Fe}(\mathrm{III})$ ions, green balls $(\mathbf{O})$ correspond to the mixture of both oxidation states, black balls $(\boldsymbol{O})$ to carbon atoms, and brown balls $(\boldsymbol{)})$ to nitrogen atoms. Voltammetric scan is the red line $(-)$.

means of the change of axial bonds of octahedral coordination polyhedrons of high-spin sites due to the modulation of their oxidation states. Thus, Fig. 5 schematizes this transition via the appearance of an intermediate state where the double-exchange mechanism is optimized: $\mathrm{PB}(\alpha=0.50$, at $0.60 \mathrm{~V})$, transition intermediate $(\alpha$ $=0.30$, at about $-0.25 \mathrm{~V})$, and ES form $(\alpha=0$, at $-0.20 \mathrm{~V})$. This new perspective is completely in concordance with the recently observed cooperative-phase transition in PB analogs during their compositional modulation from electrochemical techniques. ${ }^{65}$ This transition shows how the strong coupling between the charge, spin, and lattice degrees of freedom is the key of the charge-transfer transition from $\mathrm{Fe}$ ions explained from the double-exchange mechanism.

\section{Conclusion}

In essence, the existing relation between the spectroscopic and electrochemical measurements allows four faradaic processes plus one nonfaradaic process to be identified and quantified during the $\mathrm{PB} \rightleftarrows \mathrm{ES}$ voltammetric scan. The detected faradaic processes are associated to the exchange of hydrated protons and protons as well as to the exchange of potassium ions into two different spatial locations (structural and interstitial location). Considering real-time spectroelectrochemical data and previous electrogravimetric and structural measurements, the electrochemical reactions of the different electroactive $\mathrm{Fe}$ sites into the PB structure are here distinguished. The postulated processes are:

1. Electrochemical reactions caused by changes of the oxidation state of $\mathrm{Fe}(\mathrm{II})_{\text {low-spin }}-\mathrm{CN}-\mathrm{Fe}(\mathrm{III})_{\text {high-spin }}$ sites (Eq. 3).

2. Electrochemical reactions caused by changes of the oxidation state of $\mathrm{Fe}(\mathrm{III})_{\text {low-spin }}-\mathrm{CN}-\mathrm{Fe}(\mathrm{II})_{\text {high-spin }}$ sites (Eq. 4).

3. Two electrochemical reactions due to iron ions located next to ferrocyanide vacancies (Eq. 7 and 8).

Potassium cations show two different places for their insertion: one located in $\mathrm{Fe}(\mathrm{II})_{\text {low-spin }}-\mathrm{CN}-\mathrm{Fe}(\mathrm{III})_{\text {high-spin }}$ sites and the other in $\mathrm{Fe}^{3+}(\mathrm{NC})_{5} \mathrm{OH}_{2}$ sites next to ferrocyanide vacancies. From the monitoring of electroactive $\mathrm{Fe}$ sites, it is possible to assume that the reduction of all $\mathrm{Fe}$ sites located next to ferrocyanide vacancies is responsible for the nonfaradaic process. The PB magnetic ordering at room temperature induces a nonfaradaic current during the $\mathrm{PB} \rightleftarrows \mathrm{ES}$ voltammetric scan.
This PB magnetic ordering results because the double-exchange mechanism has optimized its performance in PB films when $\mathrm{Fe}(\mathrm{III}) /[\mathrm{Fe}(\mathrm{II})+\mathrm{Fe}(\mathrm{III})] \cong 0.30$. This offers appealing perspectives for the control of this interesting phenomenon from electrochemical techniques what could be used for the fabrication of the recent electronically configurable molecular-based logic gates employed in chemically assembled electronic nanocomputers. This work gives a picture of PB films during their voltammetric scan from an electronic exchange perspective by considering the nature of iron bonds and their electrochemical evolution.

\section{Acknowledgments}

This work was supported by FEDER-CICyT project no. CTQ2007-64005/BQU. D. Gimenez-Romero acknowledges his position at the Generalitat Valenciana.

University of Valencia assisted in meeting the publication costs of this article.

\section{References}

1. N. R. de Tacón and K. Rajeswar, Chem. Mater, 15, 3046 (2003).

2. D. M. DeLongchamp and P. T. Hammond, Adv. Funct. Mater, 14, 224 (2004)

3. K. Itaya, N. Shoji, and I. Uchida, J. Am. Chem. Soc., 106, 3423 (1984).

4. K. Rajeshwar, in Electron Transfer in Chemistry, V. Balzani, Editor, Wiley-VCH, Weinheim (2001)

5. J. Li, J. D. Qiu, J. J. Xu, H. Y. Chen, and X. H. Xia, Adv. Funct. Mater, 28, 1574 (2007).

6. P. J. Kulesza, J. Electroanal. Chem. Interfacial Electrochem., 289, 103 (1990).

7. P. R. Bueno, D. Gimenez-Romero, C. Gabrielli, J. J. Garcia-Jareño, H. Perrot, and F. Vicente, J. Am. Chem. Soc., 128, 17146 (2006).

8. D. Gimenez-Romero, J. Agrisuelas, J. J. Garcia-Jareño, J. Gregori, C. Gabrielli, H. Perrot, and F. Vicente, J. Am. Chem. Soc., 129, 7121 (2007).

9. R. J. Mortimer and J. R. Reynolds, J. Mater. Chem., 15, 2226 (2005).

10. V. Escax, C. C. D. Moulin, F. Villain, G. Champion, J.-P. Itié, P. Münsch, M. Verdaguer, and A. Bleuzen, C. R. Chim., 6, 1165 (2003)

11. S. Ferlay, T. Mallah, R. Ouahes, P. Veillet, and M. Verdaguer, Nature (London), 378, 701 (1995).

12. O. Sato, T. Iyoda, A. Fujishima, and K. Hashimoto, Science, 272, 704 (1996).

13. R. Lescouezec, J. Vaissermann, C. Ruiz-Perez, F. Lloret, R. Carrasco, M. Julve, M. Verdaguer, Y. Dromzee, D. Gatteschi, and W. Wernsdorfer, Angew. Chem., Int. Ed., 42, 1483 (2003)

14. L. Catala, T. Gacoin, J. P. Boilot, E. Riviere, C. Paulsen, E. Lhotel, and T. Mallah, Adv. Mater. (Weinheim, Ger.), 15, 826 (2003).

15. S. Hayami, Z. Z. Gu, M. Shiro, Y. Einaga, A. Fujishima, and O. Sato, J. Am. Chem. Soc., 122, $7126(2000)$

16. T. Yamamoto, Y. Umemura, O. Sato, and Y. Einaga, J. Am. Chem. Soc., 127, 16065 (2005).

17. G. Champion, V. Escax, C. C. D. Moulin, A. Bleuzen, F. O. Villain, F. Baudelet, E. Dartyge, and M. Verdaguer, J. Am. Chem. Soc., 123, 12544 (2001).

18. O. Sato, T. Iyoda, A. Fujishima, and K. Hashimoto, Science, 271, 49 (1996).

19. O. Sato, T. Kawakami, M. Kimura, S. Hishiya, S. Kubo, and Y. Einaga, J. Am. Chem. Soc., 126, 13176 (2004).

20. J. J. Garcia-Jareño, J. Navarro-Laboulais, A. Sanmatias, and F. Vicente, Electrochim. Acta, 43, 1045 (1998)

21. D. Gimenez-Romero, P. R. Bueno, J. J. Garcia-Jareño, C. Gabrielli, H. Perrot, and F. Vicente, J. Phys. Chem. B, 110, 2715 (2006)

22. K. Itaya, H. Akahoshi, and S. Toshima, J. Electrochem. Soc., 129, 1498 (1982).

23. D. Gimenez-Romero, P. R. Bueno, J. J. Garcia-Jareño, C. Gabrielli, H. Perrot, and F. Vicente, J. Phys. Chem. B, 110, 19352 (2006).

24. D. Gimenez-Romero, P. R. Bueno, J. J. Garcia-Jareño, C. Gabrielli, H. Perrot, and F. Vicente, J. Phys. Chem. B, 110, 19364 (2006)

25. J. F. Keggin and F. D. Miles, Nature (London), 137, 577 (1936).

26. F. Herren, P. Fischer, A. Ludi, and W. Halg, Inorg. Chem., 19, 956 (1980).

27. S. Ganguli and M. Bhattacharya, J. Chem. Soc., Faraday Trans. 1, 79, 1513 (1983).

28. B. Bal, S. Ganguli, and M. Bhattacharya, J. Phys. Chem., 88, 4575 (1984).

29. J. J. Garcia-Jareño, A. Sanmatias, J. Navarro-Laboulais, and F. Vicente, Electrochim. Acta, 44, 395 (1998).

30. R. J. Mortimer and D. R. Rosseinsky, J. Electroanal. Chem. Interfacial Electrochem., 151, 133 (1983).

31. H. Kellawi and D. R. Rosseinsky, J. Electroanal. Chem. Interfacial Electrochem., 131, 373 (1982).

32. A. Roig, J. Navarro, J. J. Garcia-Jareño, and F. Vicente, Electrochim. Acta, 39, 437 (1994).

33. F. F. Ferreira, P. R. Bueno, C. Gabrielli, D. Gimenez-Romero, J. J. Garcia-Jareño, and F. Vicente, Appl. Phys. Lett., 92, 264103 (2008).

34. P. R. Bueno, F. F. Ferreira, D. Gimenez-Romero, R. S. Settil-Faria, C. Gabrielli, H. Perrot, J. J. Garcia-Jareño, and F. Vicente, J. Phys. Chem. C, 112, 13264 (2008).

35. M. B. Robin, Inorg. Chem., 1, 337 (1962).

36. J. J. Garcia-Jareño, J. Navarro-Laboulais, and F. Vicente, Electrochim. Acta, 41 835 (1996).

37. P. J. Kulesza and Z. Galus, J. Electroanal. Chem., 323, 261 (1992). 
38. B. J. Feldman and R. W. Murray, Inorg. Chem., 234, 213 (1987).

39. C. Gabrielli, J. J. Garcia-Jareño, M. Keddam, H. Perrot, and F. Vicente, J. Phys. Chem. B, 106, 3182 (2002).

40. J. J. Garcia-Jareño, D. Gimenez-Romero, F. Vicente, C. Gabrielli, M. Keddam, and H. Perrot, J. Phys. Chem. B, 107, 11321 (2003).

41. J. J. Garcia-Jareño, A. Sanmatias, D. Benito, J. Navarro-Laboulais, and F. Vicente, Int. J. Inorg. Mater., 1, 343 (1999).

42. R. J. Mortimer and D. R. Rosseinsky, J. Chem. Soc. Dalton Trans., 9, 2059 (1984).

43. J. J. Garcia-Jareño, A. Sanmatias, J. Navarro-Laboulais, and F. Vicente, Electrochim. Acta, 44, 4753 (1999).

44. J. J. Garcia-Jareño, J. Navarro-Laboulais, and F. Vicente, Electrochim. Acta, 42 , 1473 (1997)

45. W. A. Gazotti, M. J. D. M. Jannini, S. I. Cordoba de Torresi, and M. A. Depaoli, J. Electroanal. Chem., 440, 193 (1997).

46. J. Agrisuelas, J. J. Garcia-Jareño, D. Gimenez-Romero, and F. Vicente, Electrochem. Commun., 8, 549 (2006)

47. J. Agrisuelas, C. Gabrielli, J. J. Garcia-Jareño, D. Gimenez-Romero, H. Perrot, and F. Vicente, J. Phys. Chem. C, 111, 14230 (2007).

48. K. Radota, A. Kalauzi, D. Djikanovi, M. Jeremic, R. M. Leblanc, and Z. G. Gerovic, J. Photochem. Photobiol., B, 83, 1 (2006).

49. M. F. Souto, F. D. Cukiernik, P. Forlano, and J. A. Olabe, J. Coord. Chem., 54, 343 (2001).

50. D. Gimenez-Romero, J. J. Garcia-Jareño, J. Agrisuelas, and F. Vicente, J. Phys.
Chem. C, 112, 20099 (2008).

51. A. Goujon, F. Varret, V. Escax, and A. Bleuzen, Polyhedron, 20, 1339 (2001).

52. A. Bleuzen, C. Lomenech, V. Escax, F. Villain, F. Varret, C. Cartier dit Moulin, an M. Verdaguer, J. Am. Chem. Soc., 122, 6648 (2000).

53. A. Bleuzen, V. Escax, J. P. Itié, P. Münsch, and M. Verdaguer, C. R. Chim., 6, 343 (2003)

54. J. B. Goodenough, Phys. Rev, 100, 564 (1955).

55. B. Mayoh and P. Day, J. Chem. Soc. Dalton Trans., 15, 1483 (1976).

56. C. Zener, Phys. Rev., 82, 403 (1951).

57. D. B. Soria, O. E. Piro, E. L. Varetti, and P. J. Aymonino, J. Chem. Cryst., 31, 471 (2002)

58. A. Ito, M. Suenaga, and K. Ono, J. Chem. Phys., 48, 3597 (1968).

59 G. Rogez, A. Marvilliers, E. Riviere, J. P. Audiere, F. Lloret, F Varret, A Goujon, N. Mendenez, J. J. Girerd, and T. Mallah, Angew. Chem., Int. Ed., 39, 2885 (2000).

60. A. Bhattacharjee, S. Saha, S. Koner, V. Ksenofontov, S. Reiman, and P. Gütlich, J. Magn. Magn. Mater, 302, 173 (2006)

61. J. J. Garcia-Jareño, A. Sanmatias, J. Navarro-Laboulais, and F. Vicente, Electrochim. Acta, 44, 395 (1998).

62. J. Bisquert, J. Phys. Chem. B, 106, 325 (2002).

63. B. Bahreyni and C. Shafai, IEEE Sens. J., 7, 1326 (2007).

64. D. S. Middlemiss and C. Wilson, Phys. Rev. B, 77, 155129 (2008).

65. F. Nakada, H. Hamioka, Y. Moritomo, J. E. Kim, and M. Takata, Phys. Rev. B, 77, 224436 (2008). 